\title{
Facility for testing ice drills
}

\author{
Dennis L. Nielson ${ }^{1}$, Chris Delahunty ${ }^{1}$, John W. Goodge ${ }^{2}$, and Jeffery P. Severinghaus ${ }^{3}$ \\ ${ }^{1}$ DOSECC Exploration Services, LLC, 2075 S. Pioneer Rd., Salt Lake City, UT 84104, USA \\ ${ }^{2}$ Department of Earth and Environmental Sciences, University of Minnesota Duluth, Duluth, MN 55812, USA \\ ${ }^{3}$ Scripps Institution of Oceanography, UC San Diego, 9500 Gilman Drive no. 0244, La Jolla, CA 92093, USA
}

Correspondence to: Dennis L. Nielson (dnielson@ dosecc.com)

Received: 12 July 2016 - Revised: 31 January 2017 - Accepted: 13 February 2017 - Published: 31 May 2017

\begin{abstract}
The Rapid Access Ice Drill (RAID) is designed for subsurface scientific investigations in Antarctica. Its objectives are to drill rapidly through ice, to core samples of the transition zone and bedrock, and to leave behind a borehole observatory. These objectives required the engineering and fabrication of an entirely new drilling system that included a modified mining-style coring rig, a unique fluid circulation system, a rod skid, a power unit, and a workshop with areas for the storage of supplies and consumables. An important milestone in fabrication of the RAID was the construction of a North American Test (NAT) facility where we were able to test drilling and fluid processing functions in an environment that is as close as possible to that expected in Antarctica. Our criteria for site selection was that the area should be cold during the winter months, be located in an area of low heat flow, and be at relatively high elevation. We selected a site for the facility near Bear Lake, Utah, USA.

The general design of the NAT well (NAT-1) started with a $27.3 \mathrm{~cm}$ (10.75 in.) outer casing cemented in a $152 \mathrm{~m}$ deep hole. Within that casing, we hung a $14 \mathrm{~cm}$ (5.5 in.) casing string, and, within that casing, a column of ice was formed. The annulus between the 14 and $27.3 \mathrm{~cm}$ casings provided the path for circulation of a refrigerant. After in-depth study, we chose to use liquid $\mathrm{CO}_{2}$ to cool the hole. In order to minimize the likelihood of the casing splitting due to the volume increase associated with freezing water, the hole was first cooled and then ice was formed in increments from the bottom upward. First, ice cubes were placed in the inner liner and then water was added. Using this method, a column of ice was incrementally prepared for drilling tests. The drilling tests successfully demonstrated the functioning of the RAID system. Reproducing such a facility for testing of other ice drilling systems could be advantageous to other research programs in the future.
\end{abstract}

1

Characterizing and mapping continental bedrock beneath the Antarctic ice sheets is a fundamental objective of the US National Science Foundation's Antarctic Program (Goodge and Severinghaus, 2016). However, drilling through thick ice using existing ice-coring equipment is a slow process that has required multiple working seasons, and these systems were not designed for recovery of sub-glacial bedrock samples. The development of a mechanical drilling system that can rapidly drill through ice and core the base of the ice sheet and underlying bedrock is a high priority for the scientific community (Clow and Koci, 2002; Gerasimoff, 2012). Other priorities include finding the oldest ice in Antarctica in order to enhance our understanding of past global climate changes by linking changes recorded in the polar ice sheets with complementary marine sediment records.

The goal of the Rapid Access Ice Drill (RAID) is to rapidly drill a thick section (up to $3300 \mathrm{~m}$ ) of Antarctic ice and to collect core samples of the transition zone and underlying bedrock. We expect to drill five or six holes in a 2-month drilling season. To accomplish this, we need to achieve penetration rates through the ice of $3 \mathrm{~m} \mathrm{~min}^{-1}$. In addition, existing equipment is only designed to core ice, whereas RAID is the first system to focus on coring the transition zone and underlying bedrock. RAID will operate autonomously in remote regions of Antarctica and therefore must be highly mobile. It includes five different components: drill skid, rod 
skid, fluid re-circulation system (FRS), power unit, and shop and supply container.

To mitigate the risks associated with the performance of this new drilling system, a series of bench and field tests were designed to evaluate individual components and system integration before deployment to Antarctica. The North American Test (NAT) was the first integrated RAID system test where drilling and fluid circulation functions were tested under conditions that were as close as possible to those expected in Antarctica. The RAID is designed to use ESTISOL140 (ESTISOL) as a drilling fluid because it has a density similar to that of ice, it has a low freezing point, and it has good transparency, allowing the hole to be logged optically following drilling (Sheldon et al., 2014). The FRS processes the returned ESTISOL and included ice chips, separates the ice, and re-circulates the ESTISOL down the hole. RAID utilizes pressurized reverse circulation to drill through the ice; i.e., ESTISOL is pumped down the annulus between the rods and ice, and the returned fluid and ice cuttings flow up the inside of the drill rods. This is done to mitigate the risk of cuttings freezing in the small annulus between the ice and the drill rod. The FRS is a key component of the fluid circulation system, and is a unique development under this project. As with all prototype equipment, it requires comprehensive testing under expected operating conditions.

In order to accomplish the RAID system test, we designed and built a facility where we could drill ice and test the rig's drilling and coring capabilities as well as the functioning of the FRS. In brief, the NAT facility consisted of a hole where we froze a column of ice and conducted a series of system tests. Other test facilities for testing ice drilling include a $60 \mathrm{~m}$ deep hole at CRREL (National Research Council, 1986) and a $13 \mathrm{~m}$ deep facility at the University of Alaska (Das and Jois, 1994). A $76 \mathrm{~m}$ deep well at the University of Wisconsin was established as part of the IceCube development and was used in early 2016 to test the ASIG drill (K. Slawney, personal communication, 2017).

The NAT facility was established on private land near Bear Lake, Utah, and was permitted through the Utah Division of Oil Gas and Mining. This site met a number of criteria. First, this region is often one of the coldest areas in the lower continental United States. We wanted to replicate temperatures that the equipment and personnel would experience in Antarctica. Second, operations in Antarctica are expected to take place at elevations of 3000 to $4000 \mathrm{~m}$. These elevations will impact the performance of both machinery and personnel; the elevation at the NAT site is $1824 \mathrm{~m}$ above sea level. Lastly, since we wished to freeze a column of ice to a depth of $137 \mathrm{~m}$, we were working against natural heat flow. Therefore, we chose a region in northeastern Utah that has relatively low heat flow $\left(60-80 \mathrm{mWm}^{-2}\right.$; Edwards and Chapman, 2013; Nielson et al., 2016).

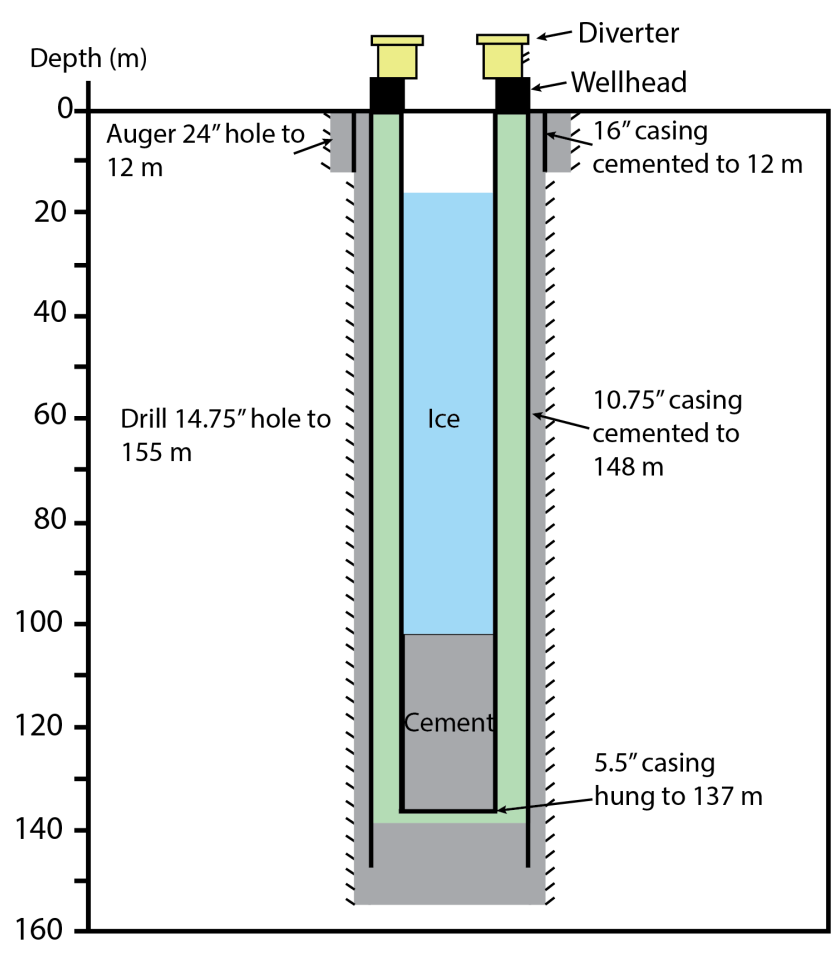

Figure 1. Schematic diagram of the North American Test facility.

\section{Facility construction}

Drilling was initiated in January, 2015, by augering a $61 \mathrm{~cm}$ ( 24 in.) hole to a depth of $12 \mathrm{~m}$ ( $40 \mathrm{ft}$ ). A $40.6 \mathrm{~cm}$ (16 in.) diameter conductor casing was cemented in place. A $37.5 \mathrm{~cm}$ (14.75 in.) hole was then drilled to total depth of $155 \mathrm{~m}$ by an Atlas Copco RD-20 rotary drill, utilizing air and foam. Then, a $27.3 \mathrm{~cm}\left(10.75 \mathrm{in}\right.$., L-80, $\left.45.5 \mathrm{lb} \mathrm{ft}^{-1}\right)$ high-strength low-carbon steel casing was cemented in place to $152 \mathrm{~m}$. The $27.3 \mathrm{~cm}$ casing was designed to separate the test hole from the bedrock to eliminate the possibility of contamination from ESTISOL. Throughout the planning process, we were concerned about the behavior of steel at very low temperature, and the volume change associated with the water to ice transition that could potentially split the casing. As a result, we chose casing that was as strong as practical. Charpy V-notch testing confirmed an average toughness rating of $177.6 \mathrm{~J}$ at $-50^{\circ} \mathrm{C}$.

A $14 \mathrm{~cm}\left(5.5 \mathrm{in}\right.$., L-80, $\left.17 \mathrm{lb} \mathrm{ft}^{-1}\right)$ casing string was designed to host the ice, and a cement plug at the bottom simulated the ice-bedrock transition. The Charpy V-notch testing on this casing produced $99.8 \mathrm{~J}$ at $-50^{\circ} \mathrm{C}$. The $14 \mathrm{~cm}$ casing was centralized and hung inside the $27.3 \mathrm{~cm}$ casing using a standard oil field wellhead. The annular space between these two casing strings formed the space for the circulation of coolant. A diverter was attached to the $5.5 \mathrm{in}$. casing to control the flow of the circulation fluid. Figure 1 shows the final, as-built NAT facility. 


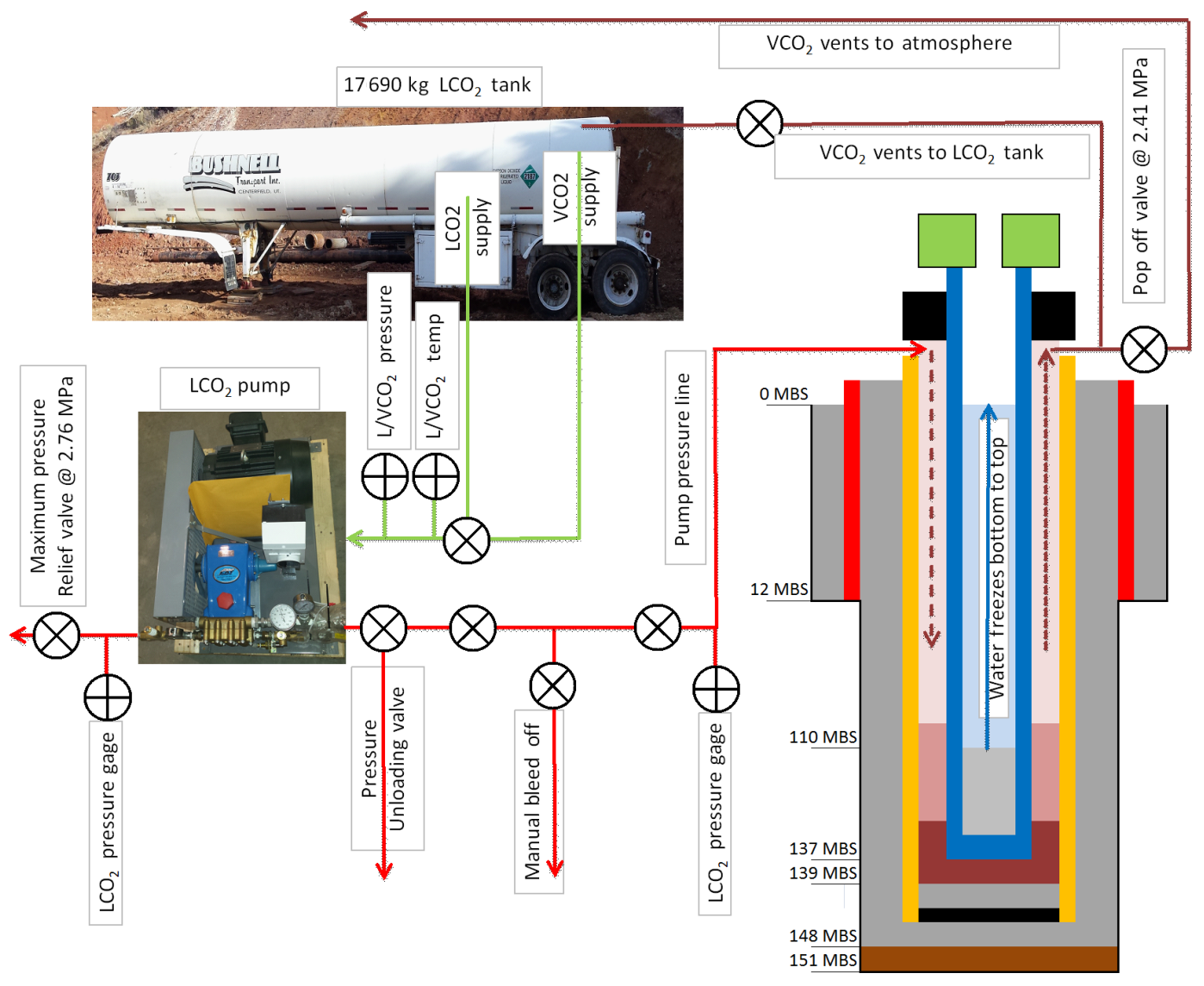

Figure 2. Cooling process diagram for the NAT facility.

A thermistor string was critical for monitoring the temperature of the well during the testing activities. A Geokon thermistor string with digital read-out at $15 \mathrm{~m}$ intervals was installed in the annular space between the 27.3 and $14 \mathrm{~cm}$ casing strings.

Liquid $\mathrm{CO}_{2}\left(\mathrm{LCO}_{2}\right)$ was selected as the refrigerant after an extensive review of different options. The basis of this selection was that $\mathrm{LCO}_{2}$ is relatively inexpensive, readily available, and pumps easily. The wellhead had choke and kill lines through which we introduced $\mathrm{LCO}_{2}$ and allowed $\mathrm{CO}_{2}$ vapor to exit. By controlling the pressure at the outlet, we were able to manage the temperatures during the cooling process. The cooling system for the facility (Fig. 2) included a $17690 \mathrm{~kg}$ (39 $000 \mathrm{lb}$.) insulated $\mathrm{LCO}_{2}$ storage tank that held $\mathrm{LCO}_{2}$ at $-20^{\circ} \mathrm{C}$ and $1.72 \mathrm{MPa}(250 \mathrm{psi})$. From this supply tank an insulated $2.5 \mathrm{~cm}$ line was connected to the suction side of the $\mathrm{LCO}_{2}$ pump. The pump could generate up to $8.27 \mathrm{MPa}$ (1200 psi) and moved the liquid from the supply tank to the inlet of the wellhead. Prior to pumping $\mathrm{LCO}_{2}$ into the well, a vapor line was connected to the well from the top of the supply tank allowing the hole to flood with $\mathrm{CO}_{2}$ vapor. This removed oxygen and moisture from the annular space and started the cooling process. The supply temperature and pressure were monitored at the pump using analog gauges. The pump had a maximum pressure relief valve on the distribution manifold that was set to $2.76 \mathrm{MPa}(400 \mathrm{psi})$. The first time we loaded the hole with $\mathrm{LCO}_{2}$ and exceeded $3.10 \mathrm{MPa}$ (450 psi), we experienced pressure that was large enough to lift the $14 \mathrm{~cm}$ casing out of the hanger wedges. This broke the seal around the $14 \mathrm{~cm}$ casing, and $\mathrm{CO}_{2}$ leaked from the annular space. To correct this issue, we used a set of chains and binders to hold the diverter down, which in turn held the $14 \mathrm{~cm}$ casing in place.

As $\mathrm{LCO}_{2}$ was introduced into the well, it absorbed heat, flashed to vapor, and the surrounding area experienced a temperature drop. Therefore, the hole cooled from the top down (Fig. 3). Once the temperature of the well was lowered to the saturation curve (equilibrium between liquid and vapor), the $\mathrm{CO}_{2}$ will remain in a two-phase liquid-vapor state. $\mathrm{Cy}-$ cling the injection allowed the annular space to be flooded by $\mathrm{LCO}_{2}$. Releasing the pressure on the hole allowed the $\mathrm{LCO}_{2}$ to flash, resulting in a decrease in temperature. Using this method, we were able to cool the entire hole. Due to the natural heat flux, it was necessary to constantly introduce $\mathrm{LCO}_{2}$ into the hole to maintain the temperature required.

Figure 3 shows the cooling history of NAT-1 starting on 5 February 2015 and following completion of the test facility. On 9 February, $\mathrm{CO}_{2}$ vapor was introduced into the annulus to 


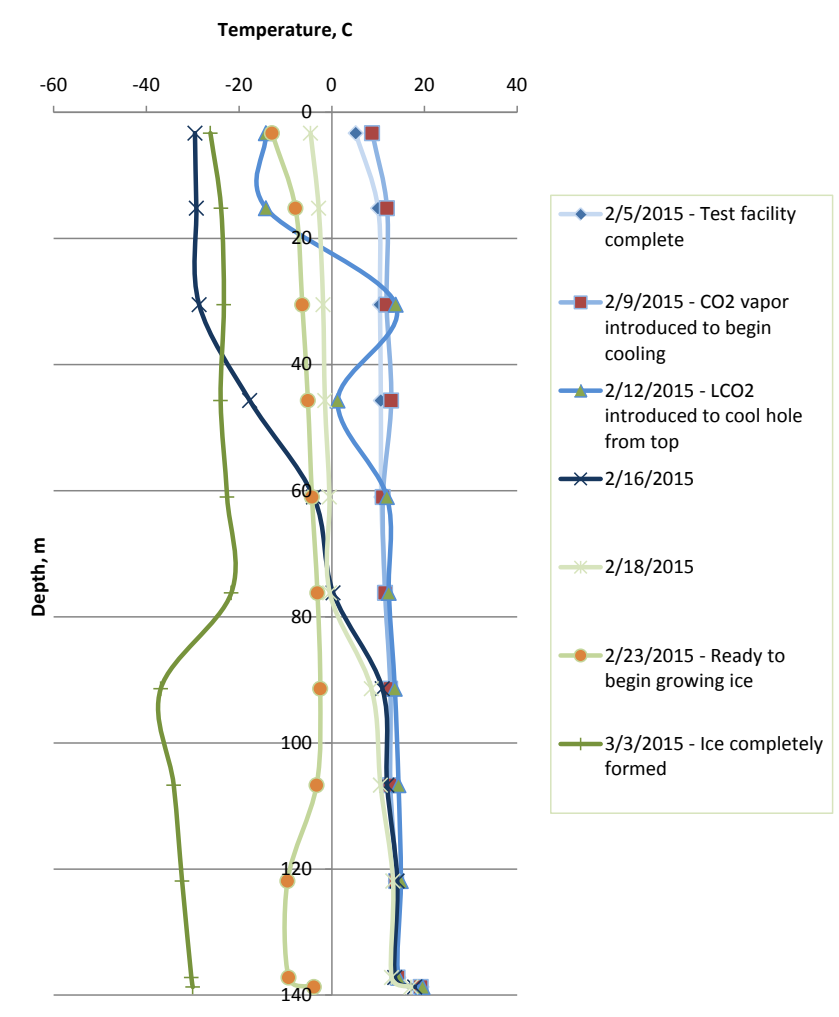

Figure 3. Temperature with depth showing the cooling history of the North American Test facility.

displace air and begin the cooling process. On 12 February, we began introducing $\mathrm{LCO}_{2}$ and cooling the hole from the top. The curve from February 23 shows the temperature profile of the hole just before we started to grow ice in the $14 \mathrm{~cm}$ casing. The final curve from 3 March shows the temperature profile once ice was formed in the $14 \mathrm{~cm}$ casing.

On several occasions we ran out of $\mathrm{LCO}_{2}$ from the main supply tank, or needed to stop cycling in order to do maintenance. This resulted in the temperature in the hole rebounding rapidly, and the cooling process had to be repeated.

Freezing water produces roughly $207 \mathrm{MPa}$ $\left(30000 \mathrm{lbs} \mathrm{in.}^{-2}\right)$ of force on the walls of a confining vessel. We were concerned that if the $14 \mathrm{~cm}$ liner burst during the freezing process, we might only get one opportunity to drill the ice. In addition to selecting steel that was as strong as possible, we decided to introduce cubed ice from the surface and then add liquid water to fill the gaps between the cubes. Although time-consuming, we believed this method would efficiently establish an ice column and reduce the strain on the liner by about $75 \%$ compared to filling it with water alone.

To calibrate the process, we added $3.2 \mathrm{~kg}$ of cubed ice to a piece of $14 \mathrm{~cm}$ casing and then added water. Together, $3.2 \mathrm{~kg}$ of ice and $2.5 \mathrm{~L}$ of water filled approximately $50 \mathrm{~cm}$ of the $14 \mathrm{~cm}$ casing. In the borehole, ice cubes were allowed to free fall to the bottom. The water, however, was a more difficult problem since it needed to be delivered to the bottom of the hole without freezing to the casing. A simple fluid dispenser was devised based on a reverse-bailer concept that would introduce approximately $53 \mathrm{~L}$ of water to the bottom of the hole using the drill's wireline. Impact of the fluid dispenser with the top of the ice released a rubber plug, and the water flowed into the ice. The freezing process then took place in $3.3 \mathrm{~m}$ increments, and the duration of a complete freezing cycle was 3 to $4 \mathrm{~h}$. A video $\log$ was run at the end of each ice-water loading cycle to verify placement and the correct depth of the ice.

\section{Testing and lessons learned}

Details of the testing procedure will be covered separately; however, the principal objectives were to evaluate bit design, to exchange a face-centered bit for coring assembly, to drill at different rates, and to confirm the functioning of the FRS. The RAID is designed to be capable of drilling rapidly through the ice in order to maximize the number of holes that can be drilled in an Antarctic summer field season. To achieve this objective, the rate of penetration is of paramount importance. The range of components that affect the penetration rate introduces too many variables to accurately determine the rate mathematically and therefore must be tested to see how hard the systems can be pushed to maximize ice drilling speed while ensuring a high degree of safety. The drilling process used an $88.9 \mathrm{~mm}$ bit and NRQ V-wall core $\operatorname{rod}(69.85 \mathrm{~mm} ; 2.75 \mathrm{in} . \mathrm{OD})$. The main parameters that have a direct effect on penetration rate are rotation speed, flow rate of the fluid circulation system, capacity of the FRS system to process debris and ice cuttings and return a clean drilling fluid, pressure exerted on the borehole to maintain the fluid flow required, and the cutting capacity of the drill bit.

Achieving progressively higher penetration rates was the chief factor guiding our testing sequence. The underlying rationale for this testing approach was that if the drill can operate successfully at its maximum penetration rate $\left(3.0 \mathrm{~m} \mathrm{~min}^{-1}\right)$, then all supporting systems are in fact functioning within specifications. A step-wise approach with progressively higher penetration rates allowed us to validate operation of each sub-system. Phase I tests at a quarter of the desired maximum speed $\left(0.75 \mathrm{~m} \mathrm{~min}^{-1}\right)$ were intended to first establish successful drilling into the ice column, and to become familiar with the system before pushing its limits. Succeeding phases were designed to validate operation at successively higher penetration rates: at halfspeed $\left(1.5 \mathrm{~m} \mathrm{~min}^{-1}\right)$ and at full speed $\left(3.0 \mathrm{~m} \mathrm{~min}^{-1}\right)$. The next phase focused on coring into the cement plug at the bottom of the ice in order to simulate bedrock coring.

Video logs were run in the hole following each test. The logs revealed an unanticipated problem with the ice-forming process. In the process of adding ice cubes and then saturating the ice with water, we observed that the top $50 \%$ of 
the $3.3 \mathrm{~m}$ segment formed compact ice, and the bottom $50 \%$ of the volume was loosely bonded ice cubes. Attempting to freeze a $3.3 \mathrm{~m}$ section was too aggressive. Water did not flow completely through the cubed ice, resulting in a section of completely frozen ice that drilled smoothly and an underlying section where the ice would break off in pre-formed cubes during drilling.

After completion of the half-speed testing segment, we refroze the hole using only water so that we could attempt to drill the full-speed test in as pristine ice as possible. We did this in increments of about $1.5 \mathrm{~m}$, and the time to freeze these segments was about 4-5 h.

Frequently, the drill bit came into contact with the casing wall, resulting in damage to the cutters on the bit. Drilling with an $88.9 \mathrm{~mm}$ outer-diameter bit in a $124.2 \mathrm{~cm}$ innerdiameter casing provided too little space for the bit to wander, and any future work should consider using a larger innercasing string.

The coring tools were tested and we were able to retrieve core, though not of the length we desired. The concrete placed at the bottom of the $14 \mathrm{~cm}$ casing was powdered by the extreme cold and was not an appropriate analog for hard rock.

Designing NAT-1 devoted a considerable amount of study to determine the best mechanism for cooling the hole. We considered the option of using a mechanically pumped coolant, such as Dynalene, in place of $\mathrm{LCO}_{2} \cdot \mathrm{LCO}_{2}$ was chosen because of lower cost and ability to reach lower temperatures through the control of pressure. However, $\mathrm{LCO}_{2}$ proved difficult to handle, and a long-term test site should consider use of a circulating refrigerant. Despite the challenges and lessons learned during experimentation, we view the creation of the NAT facility as a success that allowed for the validation of the drilling and fluid circulation components of the RAID. At the completion of the testing, the facility was plugged and abandoned. The RAID system has been shipped to Antarctica and will undergo field trials at Minna Bluff in November-December, 2016.

Competing interests. The authors declare that they have no conflict of interest.
Acknowledgements. This project was funded by the US National Science Foundation through grants 1242027 and 1419935 to the University of Minnesota Duluth. We would like to express our appreciation to Dan McClellan, Philippe Wyffels, Blaise Stephanus, and John Eckels for their contributions to the project.

Edited by: T. Wiersberg

Reviewed by: A. Pyne and one anonymous referee

\section{References}

Clow, G. D. and Koci, B.: A fast mechanical-access drill for polar glaciology, paleoclimatology, geology, tectonics and biology, Mem. Nat. Inst. Polar Research, 56, 5-37, 2002.

Das, D. K. and Jois, S. S.: Thermal modeling of ice cores and boreholes via the finite element technique, Proceedings Forth International Workshop on Ice Drilling Technology, Tokyo, Mem. Nat. Inst. Polar Research, 49, 256-280, 1994.

Edwards, M. C. and Chapman, D. S.: Geothermal resource assessment of the Basin \& Range province in western Utah, University of Utah, Department of Geology and Geophysics, 112 pp., 2013.

Gerasimoff, M. D.: Prospectus for a Rapid Access Ice Drill: a drilling system equipped for rapid transit of glacial ice, equipped for on-the-fly ice coring and suitable for regional geological mapping and glaciology, Ice Drilling Design and Operations report, University of Wisconsin, Madison, 57 pp., 2012.

Goodge, J. W. and Severinghaus, J.: Rapid Access Ice Drill: a new tool for exploration of the deep Antarctic ice sheets and subglacial geology, J. Glaciol., 62, 1049-1064, doi:10.1017/jog.2016.97, 2016.

National Research Council: Recommendations for a US ice coring program, National Academy Press, Washington, DC, 1986.

Nielson, D. L., Delahunty, C., Goodge, J. W., and Severinghaus, J. P.: Rapid Access Ice Drill (RAID), Arctic Technology Conference, St. John's, Newfoundland, OTC Paper 27324, 2016.

Sheldon, S. G., Popp, T. J., Hansen, S. B. and Steffensen, J. P.: Promising new borehole liquids for ice-core drilling on the East Antarctic high plateau, Ann. Glaciol., 55, 260-270, 2014. 